\title{
Além da estabilização \\ Do Plano Real à reconstrução da economia política brasileira
}

\section{GILSONSCHWARTZ}

Minha geração, toda ela, esteve voltada para a idéia de desenvolvimento, projeto foi a palavra mágica do existencialismo que consumimos e a constituição de um novo homem marcou nossas opções políticas. Como é possivel hoje se falar num salto para o futuro, depois da desintegração dos países do Leste europeu, quando não parece haver para o modo de produção da riqueza outra forma que não o capitalismo e quando o futuro se torna incerto e miserável, quando o presente deixa de ser o sintoma desse mesmo futuro?

(Giannotti, 1992)
RESUMO: Este artigo examina as condições econômicas gerais associadas ao processo de estabilização de preços no Brasil, chamando a atenção para questões ainda em aberto relativas ao papel do Estado e à definição de um modelo de desenvolvimento econômico. Apesar das restrições externas e da prioridade conferida à estabilidade, o autor argumenta que há espaço para definições inovadoras no campo das políticas publicas de longo prazo.
UNITERIMOS: macroeconomia, economia brasileira, estabilização, desenvolvimento, Estado, inflação.

a estabilização ao desenvolvimento, o debate está aberto. A seguir, faz-se um desmonte de armadilhas retóricas que opõem "fracassomaníacos" e "integrados". Em seguida, evidencia aspectos estruturais que fazem das relações entre Estado e mercado na economia brasileira um espaço de negociação de projetos econômicos e políticos ainda em aber-

Professor do Núcleo de Pesquisa em Relações Internacionais - USP 
1 "A Cepal sabia do processo de transformação. (...) O Prebisch entendeu a necessidade de capital externo e do papel do Estado, da substituição de importações. Economicamente, para a época, era adequado. Era preciso fazer e realmente foi feito. Eles diziam que haveria estagnação econômica - a (Maria da) Conceição Tavares, o Celso Furtado etc. Era bobagem. Iria haver (1967, começo do "milagre econômico") um ciclo de expansão, com capital externo. Não era mais "socialismo ou estagnação". Mas é o próprio FHC que, a seguir, cai em contradição, ao afirmar que em sua própria obra "(...) quando falei do subcapitalismo não tinha essa visão de que haveria desenvolvimento: para mim, ele seria castrado. No livro Empresário Industrial e Desenvolvimento Econômico no Brasil existia ainda o pressuposto da esquerda tradicional: sem autonomia nacional não existe desenvolvimento capitalista" (cf. Freire, 1996, p. 5-4). to. Nesse diagnóstico, uma compreensão mais detalhada do ciclo de investimentos em curso é decisiva. Finalmente, retomamos aspectos mais conjunturais, examinando algumas das razões para a frustração dos prognósticos mais catastrofistas que se faziam para quando houvesse o abandono da âncora cambial.

\section{“Além da Estagnação": trinta anos depois}

O presidente Fernando Henrique Cardoso, numa entrevista concedida ao jornal Folha de S. Paulo ${ }^{1}$, cometeu uma injustiça intelectual e um erro histórico, identificando uma de suas atuais críticas mais ferozes, a economista Maria da Conceição Tavares, entre os que no passado acreditaram na estagnação inescapável da economia brasileira. No caso, o presidente/sociólogo não estava propriamente dizendo "esqueçam o que eu escrevi" mas sim que "esqueci o que eu mesmo li".

Pelo menos lá está ele, citado na primeira nota ao trabalho escrito por Maria da Conceição Tavares e José Serra, Além da Estagnação ${ }^{2}$, nota mencionando um grupo que ofereceu "valiosos comentários" que "contribuíram para o enriquecimento do trabalho": Luís Souza, Cláudio Salm, Fernando Henrique Cardoso, Luís Barros e Francisco Weffort.

O objetivo maior do ensaio de Conceição e Serra era dar uma surra teórica nos "fracassomaníacos" de então, sobretudo os de esquerda, em plena ditadura militar, ao mesmo tempo reservando cascudos conceituais para o coro dos contentes da direita. FHC, que leu os originais, mesmo sem ter-se filiado à esquerda, também havia bandeado para os que acreditavam na "castração" do desenvolvimento nacional, como notamos acima.

O criticado-mor, entretanto, tinha nome e pedigree: Celso Furtado. Seu "modelo" (designado pelos autores da crítica assim mesmo, entre aspas) indicava que o esgotamento do processo de substituição de importações condenava as economias latino-americanas à estagnação. Um pensamento inaceitável em pleno processo de recuperação cíclica, uma etapa que a mitologia fascista da época designava como "milagre".

Hoje, quase 30 anos depois de "Além da Estagnação", o modelo econômico brasileiro parece oscilar entre ser uma colcha de retalhos e desandar numa geléia geral. Continua inspirando a velha pecha de que nos falta seriedade. O país ainda é o patinho feio das conferências acadêmicas e financeiras internacionais. Enquanto outros países da América Latina ou do Leste Europeu rezaram de joelhos a cartilha do ajuste neoliberal, o Brasil foi embalado numa mistura que inclui pitadas de neoliberalismo, sobrevivência do gigantismo estatal e esforços recorrentes para salvaguardar a instituição da moeda nacional.

O leque de receitas de ajuste econômico e reforma estrutural tem dois extremos: de um lado, os casos asiáticos, com políticas estratégicas de resistência ao capitalismo ocidental, de outro, os modelos ortodoxos orientados para a liberalização dos mercados e o enxugamento do Estado.

O modelo brasileiro imita o asiático no gradualismo e nas tentativas de seletividade da abertura comercial, na privatização e na liberalização relativamen- 
te mais cautelosas. Entretanto, o gradualismo seletivo das economias asiáticas está ancorado em políticas de investimento, reforma educacional e redefinição das relações entre os setores público e privado. Já no Brasil o gradualismo às vezes reflete muito mais a força dos lobbies setoriais e das alianças entre facções da elite, reflete interesses contrariados que encontram formas de evitar reformas profundas, sem uma estratégia de longo prazo transparente e consistente.

Um exemplo é o desmonte do tal modelo de substituição de importações. O Brasil seguiu a tendência internacional de renegar esse modelo (que há 30 anos já era tema de reavaliação crítica entre economistas de esquerda), mas não fez os investimentos materiais, institucionais e sociais para colocar algo melhor no lugar. $\mathrm{O}$ ajuste brasileiro acaba assim ocorrendo ao longo das linhas de menor resistência, com clara elevação dos seus custos sociais e uma evidente desnacionalização da estrutura produtiva.

Curiosamente, portanto, FHC não se lembra que a Conceição que hoje o atazana era, na época, uma crítica (ao lado de José Serra, seu ministro da Saúde) da crença politizada na estagnação e, já então, uma estudiosa dos efeitos do esgotamento do processo de substituição de importações, não sua defensora nacionalista ou eventualmente nostálgica.

Há pouco mais de 25 anos, a mensagem já era "além da estagnação". Conceição e Serra diziam com todas as letras:

Nossa idéia é de que a crise que acompanha o esgotamento do processo substitutivo representa no essencial, pelo menos no caso de alguns países, uma situação de transição a um novo esquema de desenvolvimento capitalista (Tavares \& Serra, 1980).

De fato, muitas estatísticas mostravam que a estagnação ou até o retrocesso eram comuns, sobretudo em aspectos sociais. Mas, prosseguiam nossos autores clássicos, o novo esquema de desenvolvimento:

pode apresentar características bastante dinâmicas e ao mesmo tempo reforçar alguns traços do "modelo" substitutivo de crescimento em suas etapas mais avançadas, ou seja, a exclusão social, a concentração espacial, bem como o atraso de certos subsetores econômicos quanto aos níveis de produtividade (Tavares \& Serra, 1980, p. 157).

Hoje, quando já se foi muitíssimo além da estagnação, a pergunta é outra: é possível ir além da estabilização, quando se constata que as bases da política de estabilização exigem extrema cautela na promoção do crescimento, já que por enquanto só é possível financiá-lo com “poupança externa”? Mas, se houverem alternativas, estaria a esquerda repetindo o mesmo erro outrora criticado por Conceição Tavares e Serra, de acreditar na condenação do regime por impossibilidade de superar os obstáculos ao crescimento?

É possível reconhecer novamente os traços da estagnação, do atraso e da destruição em muitos setores e subsetores. Alguns defendem uma verdadeira
2 Publicado no Brasil pela Zahar Editores do Rio de Janeiro no livro Da substituição de importações ao capitalismo financeiro - ensaios sobre a economia brasileira. $\mathrm{O}$ ensaio foi escrito em parceria com José Serra, contendo parte do material utilizado pelos autores nos cursos da Escola LatinoAmericana de Sociologia da Faculdade Latino-Americana de Ciências Sociais (ElasFlacso) e da Escolatina (Programa de Estudos de Pós-Graduação da Faculdade de Economia da Universidade do Chile). Foi apresentado no II Seminário Latino-americano para o Desenvolvimento, promovido pela Unesco e Flacso em novembro de 1970 e publicado no Trimestre Econômico de novembro/dezembro de 1971 e na Revista Latinoamericana de Sociologia em janeiro de 1972. 
"limpeza étnica" eliminando os fracos descendentes do "modelo" anterior. Mas a transição ainda está sendo negociada - aliás, os espaços de negociação ainda estão em aberto, sendo construídos. Há uma ampla "sociologia econômica" ainda em curso, depois do choque da estabilização, cuja lógica depende da restauração da capacidade do Estado arbitrar níveis de proteção, esquemas de refinanciamento de dívidas públicas e privadas, instrumentos de política industrial e tecnológica e, por fim mas não por menos, programas de distribuição de terra e renda.

Como a herança é um estoque monumental de dívidas, ampliadas pelo ciclo de euforia e crise gerado pela própria estabilização artificial da taxa de câmbio, sobretudo dívidas públicas, o saneamento financeiro é complexo e leva tempo. Se, no meio do caminho, o setor financeiro privado fosse levado de roldão, a tarefa seria ainda mais delicada, forçando sempre o Banco Central a atuar como "emprestador de última instância".

Quem sobreviverá? Quais os limites de uma política de estabilização com relação à distribuição de renda e de patrimônio? Que acertos financeiros devem ser feitos para que se estabeleçam critérios de equivalência patrimonial que permitam a recuperação do investimento público?

A ponte entre política de estabilização e reconstrução gradual de um modelo de desenvolvimento exige uma ampla e prolongada mediação estatal num momento em que, em virtude da rede de segurança armada pelos credores internacionais, públicos e privados, as pressões contra o uso político de recursos públicos são permanentes e explícitas, por meio do monitoramento do Fundo Monetário Internacional.

Essa difícil reengenharia do modelo de desenvolvimento tem sido conduzida a frio. Collor colocou em primeiro plano no imaginário nacional o desafio, senão a promessa de "chegar ao Primeiro Mundo". FHC, para surpresa geral, tem sido inepto como produtor de imagens legitimantes. A estabilização de preços é um compromisso fundamental, mas é possível ter credibilidade nesse compromisso sem outros, relativos à consistência ao longo do tempo do compromisso com o crescimento econômico? Como ir além da estabilização e como mostrar à opinião pública que este além não está depois da morte? (Keynes dizia que a longo prazo estaremos todos mortos).

A estabilização corre o risco de se tornar uma religião cultivada, surpreendentemente, por uma geração de intelectuais que depois de exilada migrou para a política. Para os críticos mais amargos, a imaginação, no poder, virou amnésia.

Entre as dificuldades inerentes à atual transição, há uma de ordem quase emocional (se é que os economistas possuem emoções). Para o "desenvolvimentista" ou "estruturalista", o discurso e os instrumentos da estabilização soam como freios, limites e incapacidade de percepção dinâmica da realidade. Já para o policy-maker que gerencia a estabilização de preços, toda demanda pode gerar "excesso de demanda" e o crescimento, subtexto da idéia de "desenvolvimento", pode ser arriscado e não apenas colocar em xeque a estabilidade como afinal revelar-se ilusório (como, em certa medida, 
foram os surtos dos anos 80 e 90 , "décadas perdidas"). Parece que surgiu uma versão pós-moderna do conflito entre estatizantes e privatistas, estruturalistas e monetaristas, industrialistas e oligarcas, abolicionistas e escravocratas e, para alguns, até mesmo da velha rixa entre paulistas e cariocas.

Mas o debate nãoé apenas doméstico. A globalização também acontece neste plano, e o mesmo debate transcorre internacionalmente. No mundo inteiro discute-se novamente a questão do crescimento, especialmente em face do que se consideram taxas medíocres nas principais economias da OCDE. Na França e em toda a União Européia discute-se o custo social do apego a uma norma monetária rígida. Nos Estados Unidos, até as estatísticas estão sendo rediscutidas pelos que pretendem repensar, diante do vigor do processo de crescimento não-inflacionário, a própria teoria do crescimento econômico.

A dificuldade maior, entretanto, parece radicar nos dilemas existenciais de uma geração que passou da aposta em projetos ao gerenciamento passivo de um presente estreito, quase imobilizada pelo espectro de um "futuro incerto e miserável". Essa geração, no poder com FHC, foi até agora incapaz de formular uma agenda votada para o que está além da estabilização.

\section{Do pragmatismo irresponsável à construção de um modelo}

Na visão de Celso Furtado, economista de uma geração keynesiana (e muito mais radicada num ambiente de "projetos existencialistas" e, depois, "estruturalistas"), um sistema econômico que perde um "motor" como a substituição de importações, sendo caracterizado por forte concentração de renda, não tem como encontrar de modo natural outra fonte de energia para sua expansão, outro fator de demanda.

Na sua visão, a tendência à estagnação viria da exaustão de uma demanda doméstica e cativa, que criava horizontes para a ampliação da oferta de produtos, através de investimentos em novas fábricas (para propiciar o atendimento dessa demanda). Furtado enxergava portanto um típico "problema de demanda efetiva", de "insuficiência de demanda" ou de "subconsumo".

Já Conceição Tavares, a rigor, atualizava em linguagem cepalina a conhecida imagem desenhada por Leon Trotsky: a dinâmica do capitalismo é a do desenvolvimento desigual e combinado, numa dimensão necessariamente mundial. Voltando ao texto de Conceição e Serra:

Diz-se, às vezes, que uma economia está estagnada ou tende a esse caminho quando seu crescimento se desacelera em determinado período. No entanto, é possível que enquanto o produto global per capita esteja crescendo a uma taxa reduzida, estejam verificando-se, no interior da economia, avanços e retrocessos significativos na evolução dos diferentes setores ou estratos econômicos, bem como surgindonovas atividades "dinâmicas". Neste sentido, a utilização da categoria "expansão" pode 
3 A declaração foi feita pela economista Lidia Goldenstein em seminário organizado em 1998 pela Sociedade Brasileira de Estudos sobre Globalização e Empresas Transnacionais (Sobeet). As palestras e debates foram gravados e arquivados pelo Conselho Regional de Economia de São Paulo. ser mais adequada que a de crescimento, visto que a primeira incluiria dentro de uma economia capitalista as flutuações cíclicas do nível de atividade econômica, bem comoo caráter desigual e combinado do desenvolvimento desse sistema (Tavares \& Serra, 1980, p. 174).

Assim, uma característica metodológica comum a Furtado e a Conceição Tavares/Serra é que ambos trabalham criticamente com o conceito de "modelo", mas tentando cada um a seu modo injetar a "variável tempo" e, de modo geral, a história no próprio modelo, traduzindo a história em forças dinâmicas distintas.

Furtado historiciza o mecanismo keynesiano da demanda efetiva, Conceição e Serra afastam-se da visão mecanicista e colocam em primeiro plano o fato de que ciclos, etapas e, de modo geral, a "expansão" capitalista são feitos de crescimento e contração, fases ou etapas que ao longo do tempo subvertem os fundamentos de cada mecanismo sem que o sistema esteja fadado à estagnação.

Em particular, Serra e Conceição alertavam para o diagnóstico que prematuramente tomasse a exclusão social como obstáculo estrutural ao desenvolvimento, como se a pobreza condenasse à pobreza:

\section{(...) poder-se-ia dizer que enquanto o capitalismo} brasileiro desenvolve-se de maneira satisfatória, a nação, a maioria da população, permanece em condições de grande privação econômica, e isso, em grande medida, devido ao dinamismo do sistema ou, melhor, ao tipo de dinamismo que o anima (Tavares $\&$ Serra, 1980, p. 158).

O texto clássico de Serra e Conceição Tavares teve esse papel crucial de reabrir o debate sobre modelos de desenvolvimento, sob o jugo feroz das ditaduras militares latino-americanas, quando quase todas as esperanças estavam exiladas e acreditar no fim do mundo ou na estagnação econômica era a forma mais evidente de negar a ditadura, ou seja, negar-lhe futuro.

Custo a crer que, numa democracia, cujo presidente participou daqueles debates e de tantos outros que vieram depois, animando a própria democratização, tenha afinal se tornado mais difícil ainda discutir modelos alternativos. Hoje se tem a impressão de que ninguém, sobretudo no governo federal, consegue ou deseja enxergar algo além da estabilização. Já cheguei a ouvir, num seminário sobre globalização e empresas multinacionais, um assessor do BNDES assumir publicamente que o governo conduz o processo de abertura econômica "aos trancos e barrancos"3.

A oposição de esquerda tem dado demonstrações igualmente constrangedoras de falta de apetite intelectual. Para ficar num exemplo recente e gritante, leia-se a seguinte abertura de um livro que tem por eixo a crítica aos anos FHC:

No Brasil, entre os anos 30 e o final dos anos 80 houve um processo de construção de um Estado nacional. Foi Collor de Mello quem iniciou, em 1990, o seu desmonte, com a adoção do ideário neoliberal. Mas a iniciati- 
va de Collor foi interrompida pelo seu impeachment. Fernando Henrique Cardoso se encarregou de levá-la a seu pleno desenvolvimento. No início de seu governo, em 1995, o Brasil era um país ainda respeitado internacionalmente, com um parque industrial significativo, com imensos recursos naturais, com empresas estatais altamente competitivas em áreas estratégicas, como a Petrobras, a Vale do Rio Doce, com um setor de Telecomunicações desenvolvido, com uma enorme rede de produção de energia elétrica, com um grande potencial de desenvolvimento e onde o trabalho era ainda o principal bem que as pessoas possuíam (Lesbaupin, 1999).

Sem entrar no mérito da periodização desajeitada, creio que por mais que se repudiem as políticas adotadas pelo governo FHC, esse tipo de afirmação é eminentemente política, ou seja, funciona mais como declaração de princípios, sem se dar ao trabalho de fazer avaliações concretas mais cuidadosas. Não há como atribuir ao período presidencial de FHC um potencial de transformação tão monumental e uma destruição tão inelutável. Estamos face à velha escatologia de esquerda, àquele mesmo espírito de condenação do país à estagnação econômica apenas porque há críticas ideológicas de fundo à aliança política dominante.

A reconstrução de um modelo de desenvolvimento continua possível, suas bases são reais e espero não ser tachado de "tucano" por buscar um diagnóstico que evite seja o catastrofismo, seja a aceitação passiva da estabilização como fim em si e último da política econômica.

A questão fundamental da segunda metade do século 20 foi a falência do Estado (cf. Schwartz, 1998). Isso é relativamente sabido e repetido, somente bolcheviques nostálgicos se arriscam a negar o fato. Mas é preciso lembrar que surgem novas formas privadas de organização da produção. Nesse processo, até os liberais foram pegos de surpresa. Pois ficou evidente que, mais que privatizar estatais, o que está em jogo nas ondas de fusões e aquisições, na reavaliação de mercados-alvo e mesmo nas decisões de caráter meramente gerencial é a capacidade de processar informação. Surge um paradoxo evidente: as novas formas de acumulação de capital são predominantemente privadas, mas o seu sucesso depende da eficiência com que se produz e distribui informação-um processo que, por definição, não pode ser exclusivamente privado!

Já é possível, cinco anos depois do Plano Real, afirmar que erraram os que apostaram em cenários de desindustrialização, desestruturação das cadeias industriais e algo que evocaria Chile e Argentina entre 1976 e 1982. De outro lado, um grupo hegemônico dizia que essa preocupação não tinha sentido e que a "obsessão com chaminés" é ultrapassada, que hoje não essa a forma de agregar valor e que o mercado saberia definir as oportunidades da economia brasileira, que os preços relativos indicariam as novas vantagens comparativas. Além disso, uma indústria que tinha sido desenvolvida apenas 
${ }^{4}$ Para esse retrato procuro me valer sobretudo das análises elaboradas pelo economista Antônio Barros de Castro, professor da UFRJ e ex-presidente do BNDES (gestão Itamar Franco). com benefícios estatais seria essencialmente dispensável e custosa.

Nenhuma das duas posições se confirmou. Aliás, o que mais chama a atenção dos especialistas em economia industrial é a continuidade setorial da economia brasileira ${ }^{4}$. Os mesmos setores são confirmados como eixos de desenvolvimento industrial:

Insumos básicos - nada mudou, as empresas são as mesmas, ainda que mudando de propriedade, as plantas são as mesmas, as mudanças de equipamento são periféricas, as escalas são as mesmas. Seja na petroquímica, no aço ou no processamento de minério, há uma enorme confirmação das opções feitas anteriormente e a cada dia surgem sinais de que o Brasil tem uma posição sólida na área de insumos básicos;

Bens de capital - mesmo aí já ocorre uma recuperação, com alguma perda em seriados, mas o setor demonstra um fôlego que revela como a sua morte anunciada estava desfocada;

Bens duráveis - é o setor mais vulnerável às oscilações do crédito no curto prazo, mas é ainda o setor automobilístico que domina a agenda de política industrial (com amplo apoio fiscal e tarifário), tem dado sinais recorrentes de disposição a investir e a se modernizar.

Em resumo, contata-se que há uma relativa resistência das cadeias produtivas e mesmo sintomas de violenta reconstituição em alguns casos, abrindo-se um novo ciclo de substituição de importações. O Brasil se caracterizou desde o surgimento da indústria automobilística como um caso de vigorosa formação de cadeias industriais. É o contrário da visão, que chegou a ser muito forte no Brasil, de que com uma economia aberta o sistema industrial organizado por cadeias setoriais seria uma idéia ultrapassada, pois cada empresa compraria onde fosse mais barato, via global sourcing, sem criar um tecido relativamente mais fechado de relações inter e intra-setoriais, propiciando uma dinâmica econômica e política interna suficientemente forte para recolocar, sim, a questão da autonomia nacional como uma das mediações decisivas do processo de desenvolvimento econômico.

Outra linha de continuidade interessante, em outro pólo de desenvolvimento, é a do setor agropecuário. No Centro-Oeste ganhou importância a produção de grãos. Muitos disseram que seria um desenvolvimento artificial, com o apoio do Estado. Hoje se vê que a região tende a centralizar a produção de grãos do Brasil, Paraná e Santa Catarina já se preocupam em como sobreviver a essa nova fronteira agrícola de competitividade crescente. Mas não se trata de uma novidade, é uma tendência que vem do final dos anos 70, com uma agricultura altamente mecanizada, uso intensivo de terra plana e clima regular.

Nada indica a falência estrutural do modelo brasileiro de consumo de massa, que se havia iniciado em 1970. Há quem alerte para uma esquisita modernidade do pobre brasileiro, sempre candidato a consumir tudo o que a classe média consome. Há uma grande unidade cultural consumista no Brasil, que é uma das bases fundamentais para decisões de investimento e ampliação da capacidade produtiva doméstica, sobretudo porque as três décadas de inflação crônica e hiperinflação reprimida tornaram a economia brasileira abso- 
lutamente retardatária em termos de crédito ao consumo.

O investimento na economia brasileira sempre esteve assentado no famoso tripé: investimento estatal, investimento privado nacional e investimento externo. Como estão ocorrendo mudanças qualitativas na própria estrutura produtiva, torna-se extremamente difícil o processo de criação de crédito e de avaliação do risco sistêmico por parte dos bancos. Some-se a isso o fato de que no Brasil o paradigma de análise de crédito ainda precisa ser criado, ou está sendo criado, depois da implosão da bolha especulativa imediatamente posterior à estabilização.

Mas sobre esse pano de fundo se soma, como um novo motor de expansão e estímulo à substituição de importações, a superação da âncora cambial. A abertura comercial e o câmbio valorizado levaram muitas empresas brasileiras a importar qualquer coisa, momentaneamente descartando fornecedores tradicionais. Superada a idiotia cambial, as cadeias entre fornecedores e produtores estão sendo reconstruídas, em muitos casos negociando agora com novos fornecedores multinacionais que compraram ou instalaram plantas produtivas locais.

Passada a fase de euforia consumista, a construção de um modelo de crescimento sustentado ainda exigirá muitas mudanças estruturais. Mas já se percebe que as grandes dores de parto são na natureza e funções do Estado, em especial na orientação dos mecanismos de crédito e financiamento, terreno onde os fatores políticos são cruciais. Mas o pleno desenvolvimento de um novo ciclo de crédito de longo prazo, ponto de partida para investimentos, depende de uma dinâmica setorial que já está em curso.

No caso do Brasil, deve-se ressaltar que ocorre sobretudo o renascimento de um sistema de planejamento que a rigor nunca deixou de existir e produzir diagnósticos (cf. Ipea, BNDES) mas que tinha menos espaço num ambiente hiperinflacionário e ficou subordinado, senão passivo, numa fase em que a estabilização e a privatização dominavam a agenda.

Já se falou muito da ausência de um "projeto nacional" como obstáculo à definição de modelos de desenvolvimento. No Brasil há um esforço claro para criar esse contexto institucional-estatal que está associado à tradição desenvolvimentista brasileira. Curiosamente, nesse mesmo momento o chamado "novo consenso de Washington" sublinha a importância do institution building. O institutional building vai lado a lado com a aplicação de uma receita conhecida como "crédito seletivo" ou policy-oriented credits, modelo que o BNDES nunca deixou de utilizar.

O BNDES pode ser uma das alavancas fundamentais, tanto no apoio diferenciado a empresas de vários setores com crédito, quanto no saneamento das finanças estaduais através de programas de antecipação de receitas de privatização. Ou seja, o Banco tem fundos e está criando crédito na economia, por canais diferenciados. O Ministério do Desenvolvimento também pode operar um projeto de abertura comercial seletiva, em que não há recuo na tarifa média, mas podem ocorrer rebalanceamentos setoriais muitas vezes cruciais 
para a sobrevivência de empresas nacionais.

Há portanto instituições estatais cruciais na montagem de um modelo de desenvolvimento que amplie as bases da estabilização, no sentido de impedir uma desestruturação e ao mesmo tempo tentar lançar bases para um crédito de mais longo prazo.

A promoção da diferenciação econômica setorial e o resgate do papel pró-desenvolvimento do Estado são dois aspectos do processo de mudança nas relações entre as três pernas do tripé: o investimento estatal, o privado nacional e o estrangeiro. Abre-se um novo "ciclo de expansão", o que não significa seja a abolição da instabilidade macroeconômica, seja a condenação do país ao atraso e à destruição patrimonial.

Na prática, ainda que de modo errático ou atendendo a pressões corporativas, tem crescido a adoção de políticas intervencionistas, assim como a manipulação das regras do jogo de mercado. Aliás, há também uma natural reação defensiva diante da deterioração das condições externas de financiamento.

Exemplos de medidas "pragmáticas" do governo brasileiro nas áreas fiscal e de contas externas:

- política setorial para produtores de equipamentos de telecomunicações;

- regime automotivo com incentivos regionais diferenciados;

- maior proteção tarifária a setores escolhidos (como brinquedos);

- restrições ao financiamento de curto prazo às importações (antes da crise);

- uso do BNDES com créditos seletivos para reconversão industrial;

- uso do BNDES para antecipar receitas de privatização a governos estaduais;

- prorrogação do Fundo de Estabilização Fiscal;

- privatizações capital-intensivas (Vale, Telecom e setor elétrico);

- redução do Imposto sobre Operações Financeiras (IOF) sobre investimentos estrangeiros;

- anúncio de política setorial para produtores de máquinas e equipamentos;

- oferta de novas linhas de crédito para exportação pelo BNDES;

- flexibilização do monopólio da Petrobras com exigências de substituição de importações e apoio à indústria local;

- resistência à aceleração do cronograma de integração das Américas.

O maior perigo, no momento atual, é acreditar que a nova configuração de preços relativos (câmbio corrigido, juros em queda, salários contidos) funciona automaticamente com indutor dos investimentos. Pode até mesmo ocorrer uma indução, mas o ciclo de investimentos será sustentável apenas se houver uma regulação estatal atenta para os impactos desses investimentos sobre as contas externas, as contas públicas e a dinâmica inter e intra-setorial.

Vários economistas de orientação menos ortodoxa têm alertado para os riscos de um ciclo de investimento espontâneo, que é incapaz de gerar me- 
canismos de financiamento mais estáveis ou de delinear perfis de acumulação minimamente consistentes, do ponto de vista macroeconômico. Estudos da própria Cepal, como os conduzidos por Ricardo Bielschowsky, têm produzido alertas nesse sentido, para os principais países da América Latina.

Esses estudos revelam que, no caso brasileiro, os investimentos cresceram em relação à medíocre primeira metade dos 90 , mas com exceção de telecomunicações, continuaram muito abaixo dos níveis médios das décadas de 70 e 80 . Os dados revelam que a indústria brasileira de fato passou por um ciclo de modernizações, em que investiu sobretudo na reposição de equipamentos e na redução de custos. Entretanto, para que esse "mini-ciclo" possa engatar-se a um ciclo de longo prazo, o Estado precisa intervir e os limites externos ao crescimento precisam ser gradualmente reduzidos.

\section{Overshooting: por que o Brasil não implodiu?}

O fim da chamada "âncora cambial" é o terceiro momento de nossa análise do Plano Real. A compreensão de como o abandono dessa política de estabilização não levou a um colapso econômico, como previam setores ligados ao governismo e ao sistema financeiro, ajuda a entender também as possibilidades ainda existentes de formulação e implementação de um projeto nacional de desenvolvimento.

O overshooting em episódios de abandono de âncora cambial é um fenômeno esperado e de curto prazo, a questão fundamental continua sendo de natureza fiscal ou, colocada de modo mais amplo, de financiamento da economia brasileira. Foi a fragilização crescente dos compromissos com o ajuste fiscal, em particular a frustração diante dos resultados efetivamente obtidos um ano depois do pacote de outubro de 1997, que retirou credibilidade da política de juros subjacente à âncora cambial. A percepção dessa fragilidade, somada às expectativas de mudanças de regime cambial que se concentraram no período pós-eleitoral (em analogia com outros casos, em especial com a flutuação do peso mexicano em 1994), minou as bases de sustentação da política econômica brasileira. A crise de confiança não resulta apenas da percepção de um evidente atraso cambial, mas também da fragilidade do Estado, questão política ampla que os economistas resumem como sendo de natureza fiscal.

Mas é preciso lembrar que, ao contrário do que ocorreu em outros casos recentes de crise cambial, no Brasil foi criada uma rede de proteção (liderada pelo FMI) que se somou a um processo de saneamento do sistema bancário que teve início logo depois da crise mexicana. Ou seja, a crise cambial brasileira seguiu o roteiro exatamente simétrico ao de casos na Ásia ou na Rússia: lá, houve fragilidade fiscal e financeira, colapso do sistema bancário e os países-líderes foram relutantes no resgate. No Brasil, em parte porque o sistema global já estava estressado e havia dois anos de aprendizado, a crise cambial irrompeu em condições mais seguras.

Internamente, o grau de endividamento das empresas brasileiras já 
se havia reduzido a um mínimo nos últimos anos, enquanto o sistema bancário passava por reestruturações após a crise mexicana. Finalmente, é importante lembrar que a economia brasileira, mesmo no período de estabilidade e afluxo de capitais externos, não chegou a gerar uma bolha especulativa, em especial no setor imobiliário.

Ou seja, sem menosprezar os custos de um ajuste cambial forte, a reestruturação produtiva e financeira dos últimos anos representa uma garantia a mais de que a adaptação ao choque de custos não transborde em problemas patrimoniais mais graves no sistema empresarial ou no sistema financeiro. Mas isso significa também que, passado o período emergencial, há muito mais graus de liberdade no relacionamento com os organismos internacionais e mesmo na efetiva utilização dos fundos externos negociados com o FMI e o G-7 para absorver as pressões de demanda por moeda estrangeira em meio ao período de transição. Trata-se, nesse caso, de uma possibilidade, cuja implementação obviamente depende de planejamento e vontade política, o que naturalmente é difícil quando a elite política tem um certo apego já tradicional ao sentimento de "castração" de projetos nacionais de desenvolvimento.

Nesse cenário, a nova armadilha consiste no governo voltar a depender da restauração de fluxos de capitais especulativos, acumulando reservas com base em operações de arbitragem de curto prazo (atração de capitais com base em juros locais muito elevados frente aos níveis internacionais) enquanto a economia real fica sujeita a freios que reduzem os investimentos diretos e estreitam até mesmo as perspectivas de privatização.

Adicionalmente, como tem sido sublinhado por inúmeros analistas, o mercado monetário brasileiro difere radicalmente de casos recentes em que houve uma conexão automática entre crise cambial e default da dívida pública, simplesmente porque no Brasil a dívida pública não está dolarizada ou sequer colocada junto a investidores externos. Ao contrário, uma das diferenças institucionais relevantes da economia brasileira é a existência de uma indústria de fundos vigorosa, dominada por investidores institucionais locais e fundos de pensão do próprio setor público. Não houve portanto um mecanismo de transmissão crítico entre a crise cambial e a rolagem da dívida pública interna, embora os níveis de endividamento público por meio de papéis corrigidos pelo dólar viessem aumentando de modo preocupante no final da gestão Gustavo Franco à frente do Banco Central.

\section{Conclusão}

A geração de políticos e intelectuais que chegou ao poder com Fernando Henrique Cardoso ainda se debate com os fantasmas do fracasso na formulação e implementação de um projeto de desenvolvimento nacional.É bastante curiosa a citação com que abrimos esse texto, em que um proeminente professor de filosofia do grupo mais íntimo de FHC formula esse sentimento de castração de modo tão radical. 
Um país cujos líderes políticos e intelectuais abdicam do desafio de imaginar novos projetos obviamente não pode ter um projeto nacional. Cinco anos depois de mais um plano de estabilização, a economia brasileira ainda pode ser descrita como um "processo de transição": nem a transformação política, nem a mudança de modelo econômico que a democratização parecia prometer ocorreram de modo satisfatório e, menos ainda, irreversível.

À esquerda e à direita, os fatores externos continuam a ser escolhidos mais freqüentemente como causas da eterna síndrome de "país do futuro". Para os críticos de esquerda, a ideologia da globalização e a instabilidade sistêmica do capitalismo internacional são obstáculos intransponíveis. Os pensadores a serviço do status quo mudam a terminologia, mas também atribuem a "choques externos" a responsabilidade por desequilíbrios numa trajetória que, supostamente, teria sido inequívoca, ainda que gradual, rumo ao equilíbrio macroeconômico.

É urgente, política e tecnicamente, dar aos fatores dinâmicos internos um peso maior que o usual, para que a lenta transição democrática brasileira cumpra minimamente as suas promessas de desenvolvimento econômico e redução da desigualdade social. Se, há 30 anos, era preciso entender essa dinâmica interna para enxergar horizontes além da estagnação, hoje, cinco anos depois do Plano Real, é possível e urgente reconstruir os horizontes de uma economia política que abra caminhos além da estabilização.

Recebido para publicação em julho/1999

ScHWARTZ, Gilson. Beyond stabilization: from Plano Real to the reconstruction of the Brazilian political economy. Tempo Social; Rev. Sociol. USP, 11(2): 83-96, Oct. 1999 (edited Feb. 2000).

ABSTRACT: This article analyses the general economical conditions associated to the process of stabilization of prices in Brazil, emphasizing some questions related to the role of the definition of a model of economical development. Even having external restrictions and a priority given to the stability, the author argues that there is still space for new definitions in long term public politics.

UNITERIMS:

macroeconomy, Brazilian economy, stabilization, development, State, inflation. 


\section{REFERÊNCIASBIBLIOGRÁFICAS}

FREIRE, Vinícius Torres. (1996) Para lembrar o que ele escreveu. Entrevista com Fernando Henrique Cardoso. Folha de S. Paulo, São Paulo, 13/10, caderno Mais!, p. 4.

Giannotti, José Arthur. (1992) Moralidade pública e moralidade privada. In: Novaes, A. Ética. São Paulo, Companhia das Letras.

LeSBAuPIN, I. (1999) O desmonte de um país. In: (org.). O desmonte da Nação, balanço do governo FHC. Petrópolis, Vozes.

Schwartz, Gilson. (1998) Nem catástrofe, nem despertar dos mágicos, São Paulo em perspectiva. São Paulo, Fundação SEADE.

TAVAres, Maria da Conceição \& SERRA, José (1980) Além da estagnação. In: (orgs.). Da substituição de importações ao capitalismo financeiro - ensaios sobre a economia brasileira. Rio de Janeiro, Zahar, p. 155-207. 